\title{
Seismic Analysis of Nonstructural Elements in Buildings Considering Different Codes
}

\author{
Nasser Zaki Ahmed
}

\author{
Eman Mahmoud
}

\begin{abstract}
Nonstructural elements of a building are usually not contributing elements in the resisting system. Accordingly, they are not given the proper attention in the structural design process. However, non-structural elements attract seismic forces and thus are subjected to damage and failure during seismic events resulting in psychological and economic implications in some critical and lifelines structures. This paper reviews and evaluates the seismic design force recommended by different international design codes. It aims at evaluating seismic safety of non-structural elements and its governing factors. Response spectrum and time history are used to simulate seismic ground motion excitation. Building is modeled as a $3 \mathrm{D}$ finite element model using ETABS program. The building response behavior is considered linear elastic. A parametric study is carried out considering multi-story buildings with different heights. The considered parameters include: building height, ground motion excitation variation, dynamic building characteristics, non-structural elements dynamic characteristics (mass and stiffness), and location of the non-structural elements through the building height. Considerable variations in values of seismic force between empirical code calculations and forces resulting from dynamic analysis of this study are reported.
\end{abstract}

Keywords - Nonstructural elements, dynamic analysis, code provisions, seismic force.

\section{Introduction}

The expression "nonstructural elements of a building" is used to describe components of the structure that are mounted on or attached to the building, but are not contributing in the resisting system. According to seismic codes provisions, these elements are classified into to three categories: architectural, mechanical and electrical components. Nonstructural elements play an important role in any building because failure in these elements after earthquake may affect the life safety and the function of the building. Also, in commercial buildings damage costs of nonstructural elements account for $65 \%$ to $85 \%$ of the total construction cost [1]. It thus clear that seismic analysis should include real presentation for all elements of the building particularly in the presence of nonstructural elements of great importance or seriousness.

Nasser Zaki Ahmed/ Asisstant Professor

Faculty of Engineering / Beni-Suef University

Egypt

Eman Mahmoud/ Graduate Studen

Faculty of Engineering / Cairo University

Egypt

Mohamed Abdel-Mooty / Professor

Faculty of Engineering / Cairo University

Egypt
Seismic international codes and specifications provide engineers with simple rules and equations for calculating forces induced by earthquake shaking on the nonstructural elements. These codes equations are based on seismic intensity; time period for both of the structure and the nonstructural elements; soil condition; height of the nonstructural elements above the base of the building as well as the total height of the building [1]. In this study, four codes are considered. These codes are the Egyptian code for calculating loads and forces on buildings ECP 2012, Eurocode 8, uniform building code UBC 1997, and the international building code IBC 2012.

The dynamic characteristics of the building have a considerable effect on the response of nonstructural element. Also, there is an interaction between the building and the nonstructural element. Thus, it is important to identify the dynamic properties of both the supporting structure and the nonstructural element before investigating the response of nonstructural element. Moreover location of the nonstructural element within the structure has an impact on the nonstructural element response [2].

This paper is aimed at evaluating seismic safety of nonstructural elements and its governing parameters. Codes provisions are presented and the forces recommended by these codes are compared. A set of buildings, with different number of floors, are selected for this study. These selected buildings are designed according to the codes provisions. The non-structural elements are modelled as a single degree of freedom system. Forces induced on the non-structural elements are studied through an extended parametric analysis. The main results of the analysis are presented and compared with codes provisions

\section{Seismic Codes Provisions}

This part of the paper summarizes the provisions for seismic design of nonstructural elements in several seismic design codes. Four building codes, including Egyptian codes for computing loads and forces on building (ECP 2012) [1], European code for design of earthquake resistance structural (Eurocode 8) [2], uniform building code (UBC 1997) [3] and international building code (IBC 2012) are reviewed during this study. Equivalent lateral force method are used on most of the design codes where the seismic force on the nonstructural elements is a percentage of the nonstructural element weight. Recommendation and design data for each of the above listed codes are summarized below:

\section{A. Egyptian Code of Practice ECP 2012:}

This design code takes into consideration the time period for building and nonstructural element, soil factor, self-weight and impotence of the nonstructural element. 
The seismic force on nonstructural elements $F_{a}$ can be calculated as follows:

$$
F_{a}=\frac{S_{a} \gamma_{a}}{R_{a}} W_{a}
$$

and

$$
S_{a}=\alpha \times S\left[\frac{3\left(1+\frac{Z_{a}}{H}\right)}{1+\left(1-\frac{T_{a}}{T_{1}}\right)^{2}}-0.5\right] \geq \alpha
$$

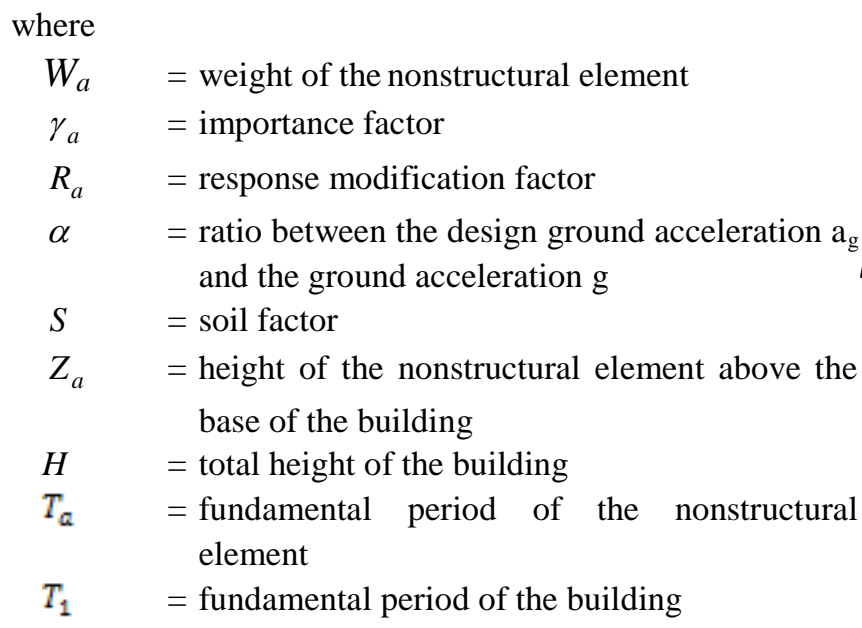

\section{B. Eurocode 8:}

Soil factor, nonstructural element self-weight, flexibility and importance factor are considered in this code. Also, the code requires realistic modeling for very important and dangerous nonstructural elements by using floor response spectra. For other elements, Eurocode 8 recommends design seismic forces, $F_{a}$, as follows:

$F_{a}=\frac{S_{a} \gamma_{a}}{q_{a}} W_{a}$

and

$S_{a}=\alpha \times S\left[\frac{3\left(1+\frac{Z_{a}}{H}\right)}{1+\left(1-\frac{T_{a}}{T_{1}}\right)^{2}}-0.5\right] \geq \alpha$

(4) E. Comments on Codes Equations:

where

$q_{a} \quad=$ behavior factor for nonstructural elements

Other factors definitions are as per ECP 2012

\section{Uniform Building Code UBC 1997:}

Seismic force, $F_{p}$, on nonstructural element can be calculated using two alternative equations as follows:

$$
F_{p}=4.0 C_{a} I_{p} W_{a}
$$

Alternatively

$F_{p}=\frac{a_{p} c_{p} I_{p}}{R_{p}}\left(1+3 \times \frac{h_{x}}{h_{t}}\right) W_{p}$

In the latter case,

$0.7 C_{p} I_{p} W_{p} \leq F_{p} \leq 4.0 C_{a} I_{p} W_{a}$

where

$C_{p} \quad=$ horizontal seismic coefficient

$a_{p} \quad=$ nonstructural element amplification factor.

$I_{p} \quad=$ importance factor of the nonstructural element.

$R_{p} \quad=$ element response modification factor.

\section{International Building Code IBC 2012:}

International building code 2012 calculates the nonstructural elements force, $F_{p}$, as follows:

$F_{p}=\frac{0.4 a_{p} S_{D S} I_{p}}{R_{p}}\left(1+2 \times \frac{z}{h_{t}}\right) W_{p}$

and

$0.3 S_{D S} I_{p} W_{p} \leq F_{p} \leq 1.6 S_{D S} I_{p} W_{a}$

where

$$
\begin{aligned}
a_{p}= & \text { component amplification factor to account for } \\
& \text { flexibility of nonstructural element. } \\
S_{D S}= & \text { spectral acceleration at short period } \\
= & 2 / 3 S_{M S} \\
S_{M S} \quad & \text { mapped considered earthquake spectral } \\
& \text { response acceleration for short periods. } \\
R_{p} \quad= & \text { response modification factor } \\
\mathrm{Z} \quad= & \text { height of point of attachment of component } \\
& \text { with respect to the base. } \\
\mathrm{h} \quad= & \text { average roof height of the building with } \\
& \text { respect to the base. }
\end{aligned}
$$

It can be noticed from the listed codes that floor acceleration is varied linearly from ground floor to roof floor. Also, roof acceleration is two to four times that of the ground floor. Inelasticity of the nonstructural elements is also considered by using response modification factor. There are different factors affecting the seismic force requirements on different codes. These factors are: seismic zone factor or component acceleration coefficient, seismic importance factor or functionality of nonstructural elements, site soil profile and element response amplification factor or response characteristics of the nonstructural elements. 


\section{Study Methodology}

This section presents the proposed methodology used in this study. A set of 6 regular buildings, presenting low to high-rise structures, are selected. A 3D finite element models are developed for these buildings using ETABS programme. Nonstructural elements are idealized as a single degree of freedom systems and mounted on the floors of the selected buildings. Ground motion is considered by using response spectrum curve given in different codes. Then, dynamic response spectrum analysis is performed using mode superposition to determine the maximum response seismic force on the nonstructural elements. Building and nonstructural elements modeling assumptions and used parameters are summarized in the following sections.

\section{A. Building Model:}

To evaluate the seismic loads on non-structural elements, a set of six reinforced concrete buildings with 5 stories, 10 stories, 20 stories, 30 stories, 40 stories and 50 stories were selected. All buildings have a 7.5 meter span arranged in 5 bays in both directions. Accordingly, the buildings dimensions are $37.5 \times 37.5 \mathrm{~m}$. Shear walls, in $20,30,40$ and 50 stories, were used in the central bay to satisfy design codes requirements. Story height is assumed $3.0 \mathrm{~m}$ in all buildings models. A 3D finite element model was constructed for each of the selected buildings. An integrated building design software ETABS was utilized in modeling and analysis. Columns and shear walls were restrained from translation and rotation in all direction at their connections to foundations. To account for cracking, bending stiffness of the elements were reduced according to the relevant used design codes. The selected buildings were designed to satisfy both of gravity and lateral loads requirements. The general layout of the selected structures are shown in Figures 1 and 2. Furthermore, summary of the main characteristics of the studied structures are given in Table 2.

\section{B. Nonstructural Element:}

Modeling of nonstructural element are left to the manufacture or the vendor, who in most of the cases, the only one familiar with the dynamic properties and substantial characteristics of the nonstructural element. Also, there are no prescribed guide or accepted standard for the modeling of nonstructural elements. In this paper a simplified but realistic model is used to idealize the nonstructural elements. Nonstructural element is modeled as lumped mass supported by single column as shown in Figure 3. Nonstructural element implied on the 3D ETABS of the building by a frame element mounted on the floor slab of the building as shown in figure 4 . The height of the nonstructural element above the building slab is assumed constant and equal one meter. Mass of the nonstructural element $\mathrm{M}_{\mathrm{a}}$ is taken $50 \mathrm{kN}, 100 \mathrm{kN}$, and $150 \mathrm{kN}$ while the fundamental period is taken $0.07 \mathrm{sec}, 0.158 \mathrm{sec}$ and 0.224 sec. the height of the nonstructural element is assumed constant and equal 1 meter

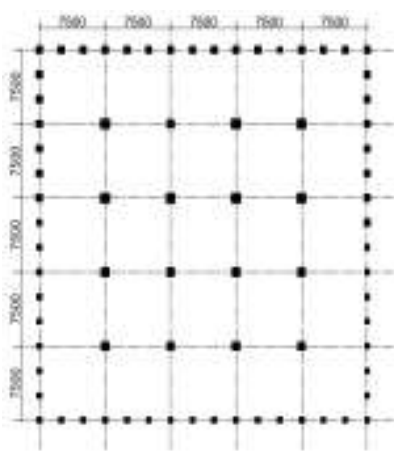

A. 5 and 10 story building

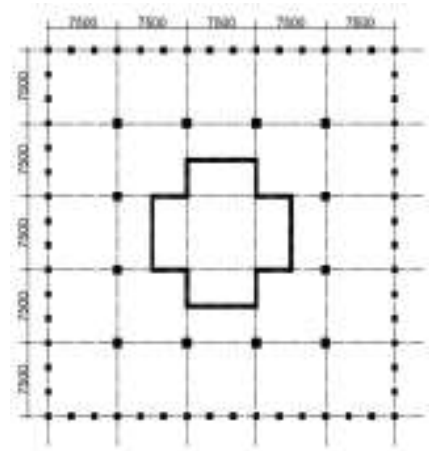

B. 30,40 and 50 story building
Figure 1. Layout of studied buildings.

TABLE I. CHARCTERSTICS OF THE STUDIED STRUCTURES

\begin{tabular}{|l|l|l|l|l|}
\hline Building & \multicolumn{1}{|c|}{$\begin{array}{c}\text { Exterior } \\
\text { Column } \\
(\mathbf{m m})\end{array}$} & $\begin{array}{c}\text { Interior } \\
\text { column }(\mathbf{m m})\end{array}$ & $\begin{array}{c}\text { Beam } \\
(\mathbf{m m})\end{array}$ & $\begin{array}{c}\text { Shear wall } \\
\text { thick. } \\
(\mathbf{m m})\end{array}$ \\
\hline 5 story & $350 \times 350$ & $700 \times 700$ & $300 \times 900$ & N.A \\
\hline 10 story & $650 \times 650$ & $900 \times 900$ & $300 \times 900$ & N.A \\
\hline 20 story & $700 \times 700$ & $1300 \times 1300$ & $300 \times 900$ & 250 \\
\hline 30 story & $700 \times 700$ & $1600 \times 1600$ & $300 \times 900$ & 300 \\
\hline 40 story & $1050 \times 1050$ & $1950 \times 1950$ & $300 \times 900$ & $600 / 250$ \\
\hline 50 story & $1200 \times 1200$ & $2250 \times 2250$ & $300 \times 900$ & $800 / 350$ \\
\hline
\end{tabular}

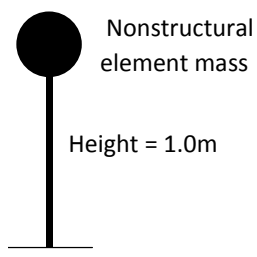

Figure 2. Idealized nonstructural element

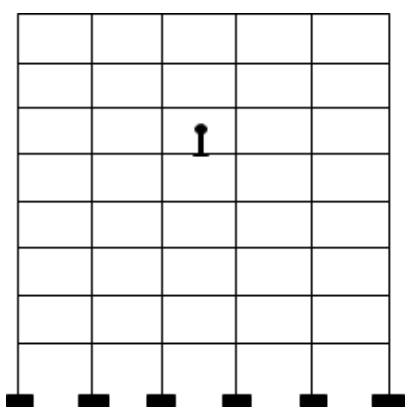

Figure 3. Modeling of nonstructural element within the building

\section{Seismic Action}

Elastic response spectrum, considering different codes, is used to simulate the earthquake action on the building and the nonstructural elements. All used response spectrum curve are scaled to their required design peak ground acceleration considering the equivalent static analysis base shear. A peak ground acceleration of 0.15 the acceleration of gravity is assumed. 


\section{Results and Discussions}

Seismic force on nonstructural elements were investigated using both the equivalent lateral force method and the dynamic analysis procedure adopted in this study.

The percentage of the seismic force to nonstructural element weight ratio resulted from the equivalent static codes equations are shown in Figure 4 for nonstructural weight mounted on level 5, 10 and 20 of 20 story building $(\mathrm{N}=20)$ and for two values of nonstructural element time period $0.07 \mathrm{sec}$ and $0.158 \mathrm{sec}$. It could be noticed that UBC and IBC are not affected by the time period of the nonstructural element.
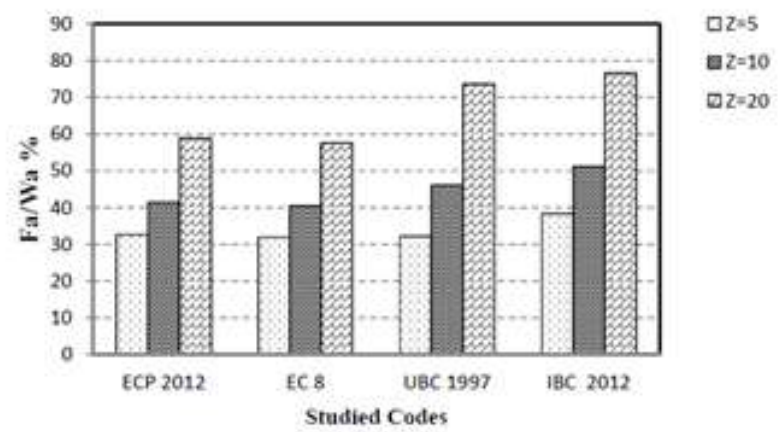

A. $\quad(\mathrm{N}=20$ and $\mathrm{Ta}=0.07 \mathrm{sec})$

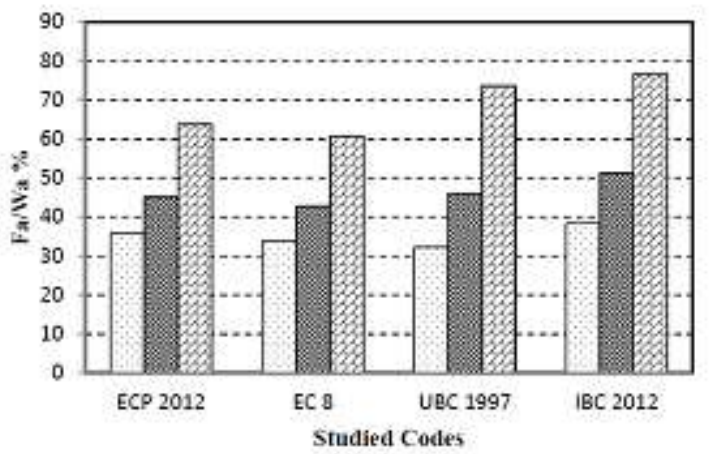

$D Z=5$

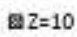

$\square Z=20$

B. $(\mathrm{N}=20$ and $\mathrm{Ta}=0.158 \mathrm{sec})$

Figure 4. Percentage of nonstructural seismic force to weight ratio using equiveleant lateral force method.

Response spectrum analysis was performed for the same building used in the equivalent lateral force where the seismic force is expressed as a percentage of nonstructural element weight. The results are displayed in Figure 5 which shows large variation using different codes as well as difference in the results when using different methods.

As a step on the way towards a better understanding of the seismic behavior of nonstructural elements, the analysis method established in this study is used to study the effect of variation of some major parametrs on nonstructural element response. The following paramters could have significant influence on nonstructural element response under earthquake effect:

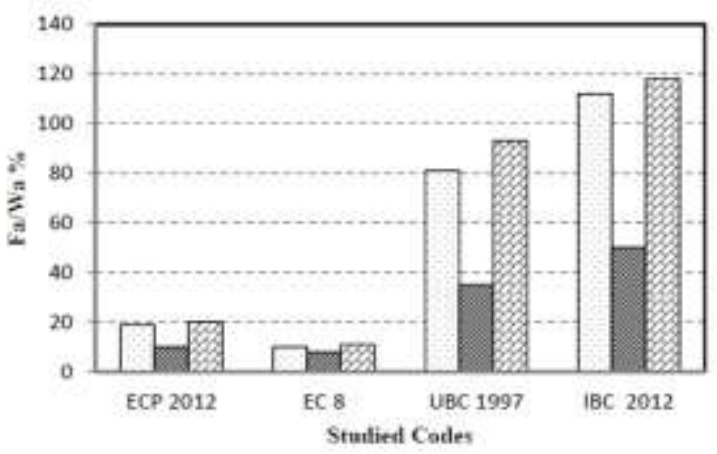

A. $(\mathrm{N}=20$ and $\mathrm{Ta}=0.07 \mathrm{sec})$

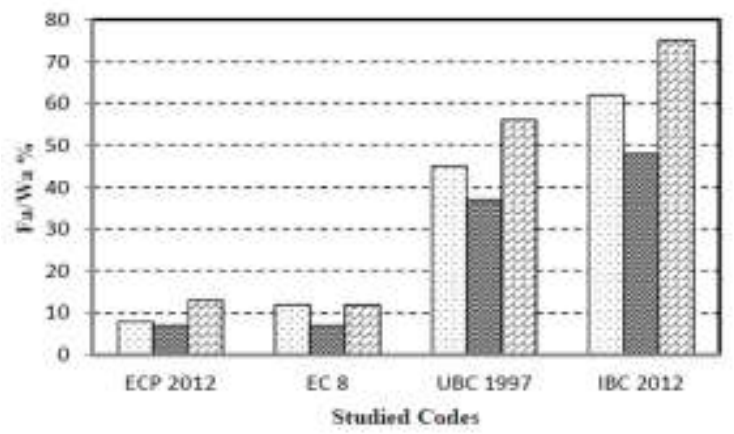

B. $(\mathrm{N}=20$ and $\mathrm{Ta}=0.158 \mathrm{sec})$

Figure 5. Percentage of nonstructural seismic force to weight ratio using response spectum analysis method.

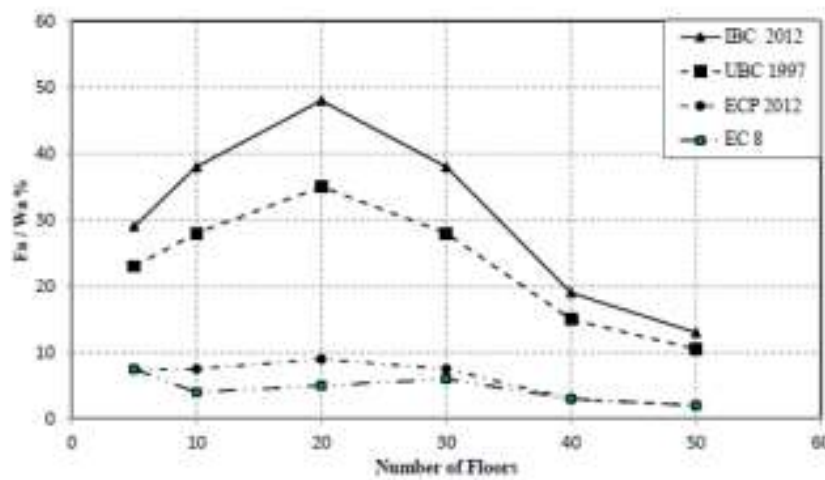

Figure 6. Percentage of nonstructural seismic force to weight ratio using (nonstructural element at $5^{\text {th }}$ floor and $\mathrm{Ta}=0.07 \mathrm{sec}$ ).

\section{A. Effect of Building Height:}

To evaluate the effect of building height on element's seismic response, a plot between normalized element seismic force $\left(F_{a} / W_{a}\right)$ and the number of floors of the supporting building is shown in Figure 6. The location of the nonstructural element was maintained on the $5^{\text {th }}$ floor level of buildings with different height. Also, the nonstructural element time period was assumed $0.07 \mathrm{sec}$ and the response was calculated considering the different codes. The change in the response is considerably low for both ECP and EC codes while a variation in response was noticed in UBC and IBC code with a peak in response at 20 story building. In addition, 
the variation in response is not of the same pattern as that of the equivalent static response values used in different codes and this indicates the necessity of using dynamic analysis in studying the response of nonstructural element located in high-rise building.

\section{B. Effect of Location of the Nonstructural element:}

The response of the nonstructural element is significantly influenced by the location of the nonstructural element as shown in Figure 7 for 20 story building and using IBC 2012 code. The maximum normalized seismic response are generally high where the nonstructural element located on roof. Also, no peak in response observed for element located at lower floors while peak is more pronounced for element at roof level. It is worthy to say that a reliable seismic response should account for the location of the nonstructural element in studying the seismic force on the nonstructural elements.

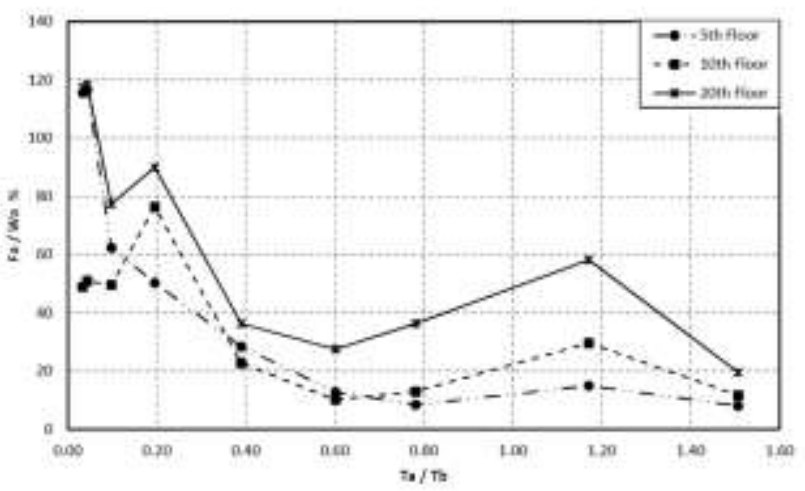

Figure 7. Effect of nonstructural element loaction $(\mathrm{N}=20$ and IBC 2012)

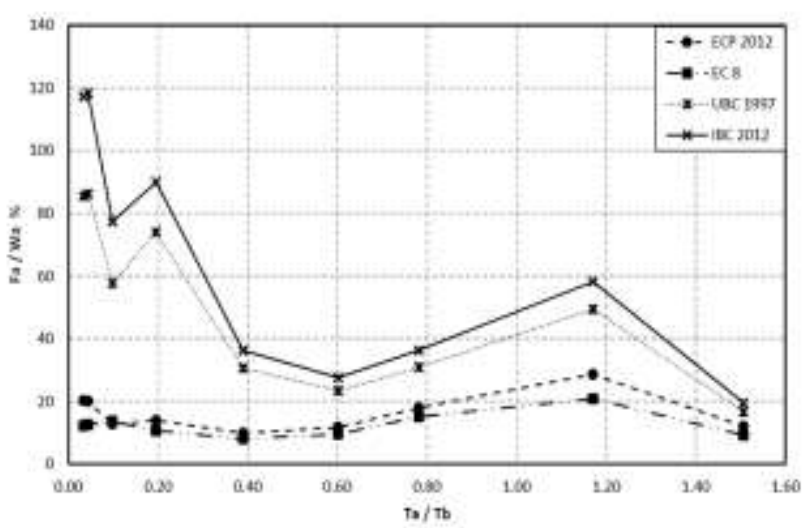

Figure 8. Effect of time period of the supporting building $(\mathrm{N}=20)$.

\section{Effect of Time Period of the Supporting Building:}

Figure 8 presents the relationship between the maximum normalized element seismic force $\left(F_{a} / W_{a}\right)$ to the ratio $\left(T_{d} / T_{b}\right)$. Seismic force is calculated for nonstructural element mounted on roof floor of 20 story building and using different codes. It could be observed that peak $F_{a} / W_{a}$ values occurs when the element is in phase with one of the modal period of the supporting structures. This observation is consist with the one discussed in other studies [7]

\section{CONCLUSIONS}

There are several conclusions that can be drawn from the numerical results presented in this paper as follows:

- Fundamental period of the building strongly influences the seismic response of nonstructural elements. Also, for elements with a constant fundamental period, the variation in element response is weakly influenced by the number of stories particularly in ECP 2012 and EC 8.

- Location of nonstructural elements should be carefully addressed in evaluating the seismic response on these elements. Response is generally higher for elements located at top floors.

- The parameter $T_{a} / T_{b}$ should be considered in quantifying and evaluating the maximum response of nonstructural elements particularly when the period of nonstructural element $T_{a}$ equal to one of the supporting building modal time period $T_{b}$.

\section{References}

[1] G., Mondal; and S., Jain, "Design of nonstructural elements for buildings: A review of codal provisionn" The indian concrete journal, pp. 22-28, Aug. 2005

[2] Y., Hibbeler; and V., Bertero "Earthquacke engineering from engineering sismology to performance based engineering", CRC Press LLC, 2006.

[3] Egyptian code of practice for computing loads and forces on structures, ECP 2012.

[4] Design of structures for earthquacke resistance part 1: General rules, seismic actions and rules for building, Eurocode 8 .

[5] Uniform building code, UBC1997, International confrence on building officilas, whittier, California, USA.

[6] International building code, IBC 2012, International code council, USA.

[7] R., Sankaranarayanan, "Seismic response of acceleration sensitive nonstructural componont mounted on moment resisting frame structures" Ph.D, University of Maryland, USA 